\title{
News \\ Challenges to understanding back pain and fibromyalgia
}

Volume 6 Issue 7 - 2016

Mohamed M Hassan

Chiropractic\& natural healing center, USA

\section{Diagnostic challenges}

As many of you already know, getting your back problem diagnosed correctly can be a challenge. To start spine specialist, don't always agree on a diagnosis, and many diagnostic tests have limited value and may even be controversial. Bottom line, there is no test that can provide an accurate back pain diagnosis, although quite a bit is known about certain conditions (e.g. a lumbar disc herniation causing sciatica).

\section{Trial and error}

Identifying the problem does not necessarily dictate the solution. There is often more than one way to treat a back condition, and finding the treatment that works best can be a process of trial and error. For example, some people with leg pain caused by a disc problem find that an epidural steroid is great pain relief, while for others it has no effect at all.

\section{Individual reactions to treatment}

Two people with identical conditions or symptoms may need different treatments. For example, two patients may have a herniated disc that looks identical on an MRI, but one may experience severe pain and disability and find that a microdiscectomy is the surest and quickest path to relief of the leg pain, while the other may find that therapy works best.

\section{Subjective experience}

Pain is a very personal experience. What may be mild back pain to one person can feel severe and incapacitating to another, and for each the level of pain needs to be treated accordingly. With all these factors, along with advances in imaging and treatments, no one doctor can be an expert in all areas of spinal problems. See Chiropractor or Specialist In Treating Back Pain. This makes it all the more important for you to educate yourself on your symptoms, conditions, and treatment options-the more you know, the better chance you have of finding meaningful and lasting pain relief.

\section{Fibromyalgia/ chronic fatigue}

\section{Definition}

Fibromyalgia is defined as the pain of the muscles and other fibrous tissue." Chronic disorder associated with pain of the muscles and related soft tissue such as ligaments and tendons where pain is generally present for at leastthree months.

\section{Key characteristics}

It is Muscle pain, Key aspect of Fibromyalgia is the presence of "tender points".

\section{Correspondence: Mohamed M Hassan, Chiropractic \& Natural Healing Center,Washington - metro area, USA, Tel 703 609305 I Email dr.mmhassan@yhoo.com}

Received: June 28, 2016 | Published: December 30, 2016

\section{Symptoms}

Chronic pain is the most common. In most people it affects the entire body, although it may start in one area such as the neck and shoulders, and spread to other areas over a period of time.

It may range from mild discomfort to pain severe enough to limit work, social activities, and everyday tasks.

\section{Symptoms of fibromyalgia can be associated with}

Headaches, especially tension and migraine headaches, abdominal pain, bloating, alternating constipation, Urinary bladder spasms, and irritability may cause urinary urgency or frequency. Changes in skin color: due to more sensitivity of skin blood circulation to temperature changes, chronic fatigue: to the point that makes simple daily activities almost impossible.

If You (Loved one or someone you know) may be experiencing moderate or severe fatigue with a lack of energy, decreased exercise endurance, orthekindof exhaustion thatresults fromthefluorlackofsleep. They may be suffering from Fibromyalgia: that kept them from participating in their life or Simple daily activities.

\section{Acknowledgments}

None.

\section{Conflicts of interest}

None. 